\title{
Meeting the old man's friend
}

\section{Antoni Torres, ${ }^{1}$ Rosario Menéndez ${ }^{2}$}

Community-acquired pneumonia (CAP) is a frequent infectious respiratory disease which remains a major cause of morbidity and mortality in developed countries. Its incidence varies and is higher at the extremes of age, both in very young children and in elderly adults. Pneumonia is more common in males than females and this difference increases with age. This is probably an effect of smoking and associated pulmonary co-morbidities. Since pneumonia is an infectious disease that does not require notification (except Legionella spp.) it is difficult to determine its incidence. Population-based studies are the best epidemiological investigations to determine the incidence of CAP. For example, Almirall and colleagues performed one such study in a region close to Barcelona, Spain. ${ }^{1}$ The incidence rate in that study was 1.62 cases per 1000 inhabitants. In another more recent study from the same group, the incidence was 1.54 cases per 1000 habitants aged $>14$ years. $^{2}$ In a study from Finland the incidence was higher, with 9 cases per 1000 inhabitants aged $>14$ years. ${ }^{3}$ The incidence of CAP varies between studies and that might reflect different populations included in the studies and different investigational methodologies used. In general we can say that the overall incidence of CAP ranges between 1.5 and 3 cases per 1000 inhabitants.

The percentage of patients with CAP requiring hospitalisation is not well known and probably varies from country to country, reflecting different criteria for hospitalisation and different resources available. In the population-based study by Almirall et al, ${ }^{1}$ the rate of admission was $61 \%$, a figure that in our opinion is very high and probably reflects practice before the widespread use of prognostic scales such as the PSI (Pneumonia Severity Index) or CURB65. There is not doubt that after the implementation of these scales for the decision regarding

\footnotetext{
${ }^{1}$ Pneumology Department, Clinic Institute of Thorax (ICT), Hospital Clinic of Barcelona, Insitut d'Investigacions Biomèdiques August Pi i Sunyer (IDIBAPS), University of Barcelona (UB), Ciber de Enfermedades Respiratorias (Ciberes), Spain; ${ }^{2}$ Servicio de Neumologia, Hospital La Fe de Valencia, Ciber de Enfermedades Respiratorias (Ciberes), Sapin
}

Correspondence to: Dr Antoni Torres, Servei de Pneumologia, Hospital Clinic de Barcelona, Villarroel 170, 08036 Barcelona, Spain; atorres@ub.edu hospital admission these figures have decreased. For example, in a more recent study from the Almirall group, only 39\% of patients were hospitalised. ${ }^{2}$

In the present issue of Thorax (see page 1062), Ewig and colleagues provide us with the most solid and largest European set of data regarding the incidence of hospitalisation for CAP. ${ }^{4}$ Based on a database of the German programme for quality in healthcare they found incidences of 2.75 and 2.96 cases per 1000 inhabitants per year in 2005 and 2006, respectively. As expected, there were more male than female cases ( $55 \%$ vs $45 \%$ ). Unfortunately, the authors did not provide data on non-hospitalised patients, and the percentage hospitalisation in relation to the total number of patients with CAP is unknown.

Beyond these important epidemiological data, there are several findings in this study that deserve comment. First of all, the authors found that the incidence of hospitalisation for CAP was 7.65 per 1000 inhabitants per year in patients aged $\geqslant 60$ years. The absolute number of patients admitted during 2 years who were aged $\geqslant 60$ years was $>300000$, a figure that confirms that CAP is a disease of the elderly population and fits very well with the much cited statement of Sir William Osler who called this disease the "old man's friend". This figure is going to increase without doubt in the next decade due to the increasing ageing of the population and consequently the increase in associated co-morbidities. These high numbers of elderly patients hospitalised for CAP represent an enormous consumption of health resources. Health authorities have to prepare plans for the next decade for dealing with this challenging frequent acute respiratory infectious disease.

Almost one-third of the patients were transferred from nursing homes. Nursing home-acquired pneumonia is one of the variables used to define "so-called" healthcare-associated pneumonia (HCAP) as stated in the last Infectious Diseases Society of America/American Thoracic Society (IDSA/ATS) guidelines for the management of CAP. ${ }^{6}$ The US concept of HCAP that implies a microbial aetiology similar to that of hospital-acquired pneumonia in terms of multiresistance microorganisms ${ }^{7}$ has recently been challenged by European studies that have not confirmed this finding. ${ }^{8}$ The risk factors for HCAP have to be reviewed and reconsidered when more information becomes available. In the meantime most of the nursing home patients have to be considered as a CAP population in terms of empirical antibiotic treatment, as indeed Ewig et al did in their study. ${ }^{4}$

Co-morbidities are very frequent in patients with CAP and obviously they increase with age. It is interesting to observe that in the study of Mandell et $a l{ }^{6}$ cardiac diseases represented the most frequent co-morbidity (19\%). Pulmonary diseases other than chronic obstructive pulmonary disease (COPD) had the third position in the ranking, but unfortunately the authors did not provide more information about the different pulmonary comorbidities grouped in this category. Only $9 \%$ of the patients had COPD, which is really surprising compared with other studies $^{10}$ and given the increased incidence of CAP in patients with COPD. ${ }^{11}$ Although it is unclear from the study of Ewig et al if all COPD patients in fact really had COPD (spirometric data are not provided) the advances in the healthcare of these patients observed in the last decade which include better treatment of the stable disease and higher rates of influenza and pneumococcal vaccination may explain this finding. ${ }^{12}$

The overall mortality found in the study of Ewig et al was 14\%, a figure that seems very high. When patients from nursing homes and the chronically bedridden were excluded from the analyses the overall mortality dropped to $8 \%$, a figure more congruent with the findings of other recent European studies that excluded nursing home patients. ${ }^{13}$ However, in a large similar study performed in the USA ${ }^{14}$ including 623718 hospitalised patients with CAP aged $\geqslant 65$ years (and also including nursing home patients) mortality was only $10.6 \%$.

Mortality varied within hospitals from 0 to $35-40 \%$, which raises two hypotheses to explain this finding: (1) populations varied within hospitals and (2) the standard of care was very different between centres. The 2007 IDSA/ATS guidelines recommend monitoring mortality of hospitalised patients with CAP according to the predicted mortality by the PSI or CURB65 scales, $^{6}$ a quality of care measurement that should be implemented in European hospitals.

Very interestingly, mortality was stratified by co-morbidities. The acute mortality of patients with COPD was the 
lowest $(10 \%)$ within patients presenting co-morbidities and lower than the overall mortality. This finding reopens the debate about the low acute mortality of patients with COPD presenting with CAP. In fact COPD was a protective factor for treatment failure in one study. ${ }^{15}$ Although the rate of acute treatment with steroids in patients with COPD is not reported in the study of Ewig et al, it is highly likely that a high percentage of them could have received such treatment, which could have attenuated the lung and systemic inflammatory response leading to a lower mortality. ${ }^{16}$ On the other hand, recent information suggests that despite the fact that previous inhaled steroid treatment may increase the risk of hospitalised $\mathrm{CAP}^{17}$ it may be associated with lower CAP severity and consequently lower mortality. ${ }^{18}$

The number of patients requiring mechanical ventilation was lower compared with other studies, particularly in advanced ages. As recognised by the authors, this could be due to treatment limitations such as "do not resuscitate" orders, or avoiding intensive care unit admission in older ages and severely disabled strata. This issue could not be analysed in detail by the authors. These are factors that might have influenced the high mortality of German hospitalised patients with CAP in this large study. This is a common error in most retrospective studies of CAP. For future studies it is highly recommended to record these two variables in order to interpret reliable data on mortality more precisely.

Finally, this study confirms in a large population the good performance of CRB65 to predict mortality in CAP in a threeclass pattern, a score much easier and less tedious to calculate than the $\mathrm{PSI}^{19}$ and which further simplifies similar scores such as CURB and CURB-65.

The data presented by Ewig et $a l^{4}$ are currently the most solid and informative data available about hospitalisation rates in patients with CAP. The information reported in this study reminds us that this is an acute illness which occurs particularly in the elderly, a population which is going to increase in the next decades. CAP in this population currently represents an enormous economic and healthcare burden, and this burden will increase substantially in future years. Programmes of prevention are the only effective way to decrease the magnitude of this problem.

Funding: Ciber de Enfermedades Respiratorias (Ciberes); el Ciberes es una iniciativa del ISCIII.

Competing interests: None.

Provenance and peer review: Commissioned; not externally peer reviewed.

Thorax 2009;64:1016-1017.

doi:10.1136/thx.2009.118299

\section{REFERENCES}

1. Almirall J, Bolibar I, Vidal J, et al. Epidemiology of community-acquired pneumonia in adults: a populationbased study. Eur Respir J 2000l;15:757-63.

2. Almirall J, Bolibar I, Serra-Prat M, et al. New evidence of risk factors for community-acquired pneumonia: a population-based study. Eur Respir J 2008;31:1274-84.

3. Jokinen C, Heiskanen L, Juvonen $\mathrm{H}$, et al. Incidence of community-acquired pneumonia in the population of four municipalities in Eastern Finland. $A m \mathrm{~J}$ Epidemiol: 137:977-88

4. Ewig S, Birkner N, Strauss R, et al. New perspectives on community-acquired pneumonia in 388406 patients. Results from a nationwide mandatory performance measurement programme in healthcare quality. Thorax 2009;64:XXX-XX.

5. Osler W. The principles and practice of medicine. New York: D. Appleton and Company, 1901.

6. Mandell LA, Wunderink RG, Anzueto A, et al. Infectious Diseases Society of America/American Thoracic Society consensus guidelines on the management of community-acquired pneumonia in adults. Clin Infect Dis 2007;44(Suppl 2):S27-72.
7. Kollef MH, Shorr A, Tabak YP, et al. Epidemiology and outcomes of health-care-associated pneumonia: results from a large US database of culture-positive pneumonia. Chest 2005;128:3854-62.

8. Carratala J, Mykietiuk A, Fernandez-Sabe N, et al. Health care-associated pneumonia requiring hospital admission: epidemiology, antibiotic therapy, and clinical outcomes. Arch Intern Med 2007;167 1393-9.

9. Venditti M, Falcone M, Corrao S, et al. Outcomes of patients hospitalized with community-acquired, health care-associated, and hospital-acquired pneumonia. Ann Intern Med 2009;150:19-26.

10. Celis MR, Torres A, Zalacain R, et al. [Diagnostic methods and treatment of community-acquired pneumonia in Spain: NACE study]. Med Clin (Barc) 2002;119:321-6.

11. Soriano JB, Visick GT, Muellerova $\mathrm{H}$, et al. Patterns of comorbidities in newly diagnosed COPD and asthma in primary care. Chest 2005;128:2099 107.

12. Alfageme I, Vazquez $\mathrm{R}$, Reyes $\mathrm{N}$, et al. Clinical efficacy of anti-pneumococcal vaccination in patients with COPD. Thorax 2006:61:189-95.

13. Dambrava PG, Torres A, Valles X, et al. Adherence to guidelines' empirical antibiotic recommendations and community-acquired pneumonia outcome. Eur Respir J 2008;32:892-901.

14. Kaplan V, Angus DC, Griffin MF, et al. Hospitalized community-acquired pneumonia in the elderly: ageand sex-related patterns of care and outcome in the United States. Am J Respir Crit Care Med 2002;165:766-72.

15. Menendez R, Torres A, Zalacain R, et al. Risk factors of treatment failure in community acquired pneumonia: implications for disease outcome. Thorax 2004;59:960-5.

16. Confalonieri $\mathbf{M}$, Urbino $\mathrm{R}$, Potena $\mathrm{A}$, et al. Hydrocortisone infusion for severe communityacquired pneumonia: a preliminary randomized study. Am J Respir Crit Care Med 200;171:242-8.

17. Ernst P, Gonzalez AV, Brassard P, et al. Inhaled corticosteroid use in chronic obstructive pulmonary disease and the risk of hospitalization for pneumonia. Am J Respir Crit Care Med 2007;176:162-6.

18. Malo de Molina R, Mortensen EM, Copeland LA, et al. Outpatient inhaled corticosteroid (ICS) therapy decreases mortality in patients with chronic obstructive pulmonary disease (COPD) and pneumonia. ATS International Conference. San Diego, California. May 15-20, 2009.

19. Capelastegui A, Espana PP, Quintana JM, et al. Validation of a predictive rule for the management of community-acquired pneumonia. Eur Respir $J$ 2006;27:151-7

\section{Thorax 2009: another great year!}

\section{J A Wedzicha, S L Johnston}

We are delighted to be able to let you all know that Thorax has continued to have a very successful past year. As usual, we nervously awaited the impact factor announcements in June 2009 and we were all delighted with the news that surpassed our expectations that our impact factor for 2008 had risen to the highest ever for Thorax at 7.069. This increase in the impact

Correspondence to: Professor J A Wedzicha, Thorax Editorial Office; j.a.wedzicha@medsch.ucl.ac.uk factor is due to the high quality papers and reviews that you have all submitted to the journal for publication. We have thus maintained our position as the second highest ranked respiratory journal in terms of impact factor, behind the American Journal of Respiratory and Critical Care Medicine. During the last year, we have published a number of original papers and guidelines that are likely to be highly cited, and we can see the Thorax impact factor rising even further in June 2010. Please continue to send us your very best papers over the coming year.

There has been a sharp rise in the numbers of submissions to the journal over the past few months that may reflect the rise in impact factor and we have nearly 1600 submissions over the past year, which is the highest number of submissions ever received by the journal. As usual the submissions come from all over the world and we are continuing to see a rise in submissions from outside Europe. BMJ Publishing have also introduced a "Portal" whereby authors can submit to more than one journal. In the event of rejection by the first-choice journal, papers and any associated peer reviews in the event of rejection are 